\title{
The spatial pattern of climate change during the spread of farming into the Aegean
}

\author{
Nicolas Gauthier \\ School of Human Evolution 85 Social Change, Center for Social Dynamics $\&$ Complexity, Arizona State \\ University, USA
}

\begin{abstract}
I examine the relationship between the spatial pattern of aridification in the northeastern Mediterranean ca 8,600 years ago and the spread of Neolithic farmers into the region surrounding the Aegean Sea. I use a generalized additive model to downscale winter rainfall from a state-of-the-art paleoclimate simulation. The model performs well at reproducing the present-day pattern of rainfall in the northeastern Mediterranean, and it generates physically-interpretable estimates of past rainfall consistent with global and regional proxy records of early Holocene climate. Comparing modeled rainfall with Neolithic settlement patterns reveals spatially-heterogeneous regional impacts of this period of global aridification. Only the humid regions of the Aegean coast experienced major drought, while more inland zones temporarily experienced more rainfall. The result of this spatially heterogeneous climate event was, conversely, more homogeneous regional rainfall. Neolithic colonists from southwest Asia would have encountered new landscapes with a more familiar, and predictable, precipitation regime.
\end{abstract}

Keywords:

Neolithic dispersal, paleoclimate modeling, statistical downscaling

\section{Introduction}

The early farmers of southwest Asia expanded into the Aegean littoral - western Anatolia, 3 Greece, and Thrace - during a period of global climate change starting 8,600 years ago. 4 This period of cooling and aridification is distinct from the rapid-onset global cooling event 5 beginning 400 years later (the " 8.2 ka event", where ka is 1,000 years before present) (Rohling 6 and Pälike, 2005). Although the increases in aridity after 8.6 and $8.2 \mathrm{ka}$ are often conflated 7 in discussions of Neolithic dispersal, the former period of climate deterioration is more s consistent with the chronology of the expansion of farming into the Aegean littoral and 9 beyond (Düring, 2013; Weninger et al., 2014; Flohr et al., 2016). For thousands of years prior to this period, farming had failed to spread along the maritime and terrestrial networks

Email address: Nicolas.Gauthier@asu.edu (Nicolas Gauthier)

Preprint submitted to Journal of Archaeological Science

August 13, 2016 
connecting the Aegean to the Neolithic core zones of southwest Asia (Schoop, 2005; Brami, 2014); in the millennium that followed, founder populations of Aegean farmers gave rise to farming communities across the Mediterranean and Europe (Hofmanová et al., 2016).

Several studies have sought to connect this drought to the Neolithic dispersal directly, with a general focus on the potential social impacts of this climate event (Clare and Weninger, 2010; Düring, 2013; Lemmen and Wirtz, 2014). Less attention has been given to the nature of the drought itself, and its manifestation on the regional and local scales most relevant to Neolithic societies. Although there are clear spatiotemporal patterns in the initial expansion of farming from the Near East (Brami, 2014; Flohr et al., 2016), the current state of paleoclimate knowledge precludes a direct comparison between the archaeological record and patterns of regional climate change.

Previous studies examining the relationship between climate change and Neolithic dispersal (e.g. Weninger et al., 2014; Flohr et al., 2016) have been limited by the use of scattered, point-based paleoclimate proxy records such as speleothems and lake cores, coupled with an assumption that the spatial patterns of climate in the present are sufficient to understand climate patterns of the past. The use of point-based proxies restricts researchers to a onedimensional perspective of climate as it changes over time and not across space. One method to spatialize proxy data is to select a set of "representative" proxy records from multiple regions of interest (Shennan et al., 2013; Lemmen and Wirtz, 2014). But extrapolating a climate signal from a single proxy to an entire region is unreliable, and imposes a spatial structure on the data a priori. Proxy data are noisy and variably time- and space-averaged records of an actual climate signal. Whether a particular proxy is sensitive to local, regional, or global climate varies with the type of proxy and its location. The geophysical and biophysical processes that formed a proxy record and the taphonomic processes that altered it are often uncertain. If the relationship between a climate signal and a proxy signal is nonlinear, this uncertainty can negatively impact the performance of statistical methods used to recover that climate signal (Tingley et al., 2012).

Proxy data are simply ill-suited to represent spatial heterogeneity in climate. But spatial heterogeneity drives ecological processes (Pickett and Cadenasso, 1995), and changes in the spatial pattern of rainfall can impact local ecologies without any change in the average values recorded in a proxy. Droughts in particular have a complex spatiotemporal structure, and ignorance of this structure will confound any attempt to model the social impacts of a drought event. To assess the role of such a drought in the spread of the Neolithic into the Aegean, we must know what rainfall was like across the landscapes settled by Neolithic groups before and after the onset of climate change 8,600 years ago.

In this paper I use a general circulation model (GCM) simulation and statistical downscaling tools as an alternative to paleoclimate proxies to examine the spatial structure of winter rainfall over the northeastern Mediterranean from 10.5 to 7 ka. GCMs produce physically-consistent estimates of past climates by coupling representations of the Earth's atmosphere, ocean, and land surface systems (Gettelman and Rood, 2016). GCMs are spatially explicit, and thus better-suited to investigate the role of climate change in the spread of Neolithic communities into the Aegean. Statistical downscaling is a computationally inexpensive method to generate high-resolution fields from spatially coarse GCM outputs 
(Wilby et al., 2004; Maraun et al., 2010). After comparing the spatial pattern of downscaled model outputs to a dataset of Neolithic settlement locations, I find that the climate change in the northeastern Mediterranean around 8.6 ka would have led to a more regionally homogeneous winter rainfall regime and facilitated movement of Neolithic farmers through a range of previously distinct environments.

\section{Methods}

\subsection{Statistical Downscaling}

The computational complexity of GCMs demands a trade-off between spatial resolution and the number of simulated years. Simulations spanning several millennia are generally run at resolutions of greater than $1^{\circ}$ at the equator to minimize computational time. Output from these simulations must be downscaled to a higher resolution to detect climate patterns at regional scales. Two common downscaling techniques are dynamical and statistical downscaling.

Dynamical downscaling embeds a high-resolution regional climate model in a standard low-resolution GCM so that the region of interest is represented in much more detail than the rest of the globe (e.g. Brayshaw et al., 2011). Although regional models retain the dynamical nature of GCMs, they are even costlier to run than GCMs in terms of time and money. Furthermore, the choice of regional climate model parameters and boundary conditions introduces an additional level of uncertainty to the GCM outputs.

Statistical downscaling is a much more flexible alternative to regional climate modeling. These techniques build a statistical relationship between small-scale observed climate and large-scale GCM simulations of the same period, then use this relationship to infer smallscale climate from GCM simulations of a different period (Wilby et al., 1998). A generalized additive model (GAM) is one kind of statistical model that can effectively downscale GCM data (Brulhet et al., 2003; Vrac et al., 2007). GAMs are primarily data driven, in contrast to weather generators and other statistical downscaling methods that rely to a greater degree on external assumptions and parameterizations (Vrac et al., 2007). GAMs can also process gridded data; other techniques are often point-based and thus not spatially continuous.

In a GAM, an observed climate variable is modeled as a function of multiple explanatory variables. This technique is conceptually similar to multiple linear regression, but linear regression assumes linear relationships between observed and explanatory variables with normally-distributed errors, whereas a GAM uses smooth polynomial functions and "link" functions to account for nonlinear relationships and non-normal errors, respectively. GAMs have previously been used to downscale GCM simulations of the Last Glacial Maximum in Europe (Vrac et al., 2007; Levavasseur et al., 2011; Korhonen et al., 2013; Burke et al., 2014). These studies used GAMs to predict past climate conditions as a nonlinear function of atmospheric variables from a GCM, small-scale topography derived from a digital elevation model (DEM), and interactions between the two. The logic behind this implementation is that if local climate heterogeneity arises from the interaction of local topography and dynamic regional atmospheric circulation, and both topography and its statistical relationship to local climate are effectively static through time, then a statistical model calibrated on 
modern-day climates can downscale GCM atmospheric data from any time period (Wilby et al., 2004). GAMs have yet to be used to downscale Holocene climate simulations, but this time period is a more reasonable target then glacial climates because the assumptions of static topography and stable statistical relationships are better satisfied.

\subsection{General Circulation Model}

The GCM data to be downscaled were derived from the TraCE-21ka simulation of the Last Glacial Maximum to the present (He 2011). This simulation used version 3 of the National Center for Atmospheric Research's Community Climate System Model (CCSM3). CCSM3 models the dynamic interactions between the atmosphere, ocean, sea ice, and land surface on a global scale (Collins et al., 2006). In the TraCE-21ka simulation, CCSM3 was run for the period from 22 ka to AD 1990 at a horizontal resolution of approximately $3.75^{\circ}$ at the equator. It is a transient simulation in that boundary conditions and forcings were varied over time to simulate the real-world climate evolution over the past 20,000 years. This is in contrast to an equilibrium simulation in which climate forcings are held constant and the model is allowed to reach an equilibrium state without successive external inputs (an approach more common for Regional Climate Model applications to paleoclimates (Brayshaw et al., 2011)). Climate changes in TraCE-21ka were forced by greenhouse gases, changes in the Earth's orbit, and fluxes of glacial meltwater. The simulation's boundary conditions included ice-sheet extent and sea level. From this combination of transient and static inputs, TraCE-21ka reproduced key events of the last deglaciation including the Younger Dryas and Bølling-Allerød warm period (He, 2011).

Simulation outputs of decadal-mean winter averages of large scale precipitation (PRECL in CCSM3), convective precipitation (PRECC), and zonal and meridional wind velocities (U and V) were downloaded from the Earth System Grid Repository ${ }^{1}$ for the periods 10.5 to $7 \mathrm{ka}$ and AD 1950 to 1990 for GAM prediction and calibration, respectively. Winter rainfall was chosen as the specific downscaling target because most of the region's annual precipitation occurs in winter, and the paucity of summer rainfall would necessitate a more complex GAM that accounts for both the occurrence and amount of rain.

\subsection{Model Selection and Fitting}

The observed climate data used as a target for the GAM were present-day climatologies of precipitation in a winter month (December, January, and February), in millimeters, at $5^{\prime}$ resolution (approximately $10 \mathrm{~km}^{2}$ ) developed by the WorldClim Project (Hijmans et al., 2005). The $5^{\prime} \mathrm{DEM}$ included in the WorldClim dataset was used to derive the topographic predictors, and is itself a derivative of the SRTM global DEM.

The topographic predictors used in the GAM were elevation, Euclidean distance to the sea, and distance to the sea in the mean wind direction. The latter two variables approximate the diffusive and advective continentality indices used in previous studies, respectively (Vrac et al., 2007; Levavasseur et al., 2011). Advective continentality approximates the

\footnotetext{
${ }^{1}$ https://www.earthsystemgrid.org/project/trace.html
} 
changing wetness of marine air masses moving across land and captures the impact of Atlantic westerlies on winter precipitation. This index thus encodes information from both the GCM and DEM, allowing the downscaling procedure to generate local-scale heterogeneity beyond that imposed by present-day topographic gradients (a limitation of the commonlyused change factor downscaling approach (Wilby et al., 2004)). Elevation and diffusive continentality were derived directly from the DEM; advective continentality was calculated using the DEM and U and V variables from TraCE-21ka. All preprocessing was carried out using the raster package in $\mathbf{R}$ (Hijmans, 2016; R Core Team, 2015).

The physical predictors from TraCE-21ka were bilinearly interpolated to the $5^{\prime}$ resolution of the WorldClim data to allow for direct comparisons at each grid point (see Vrac et al., 2007). All predictors and predictands were clipped to land areas between longitudes E20 and $\mathrm{E} 35^{\circ}$ and latitudes $\mathrm{N} 34^{\circ}$ and $\mathrm{N} 43^{\circ}$ (Fig. 1).

A GAM was fit to the predictor and predictand data for present-day climates using the mgcv package in $\mathbf{R}$ (Wood, 2006, 2011). The observed precipitation data were defined as gamma-distributed with a log-link function. Rainfall intensities generally follow the gamma distribution (Alemán et al., 1981), and defining a log-link effectively log-transforms the rainfall data prior to model fitting. Penalized cubic regression splines were used to represent the nonlinear relationships between the predictand and each predictor, and the parameters for these splines were estimated using a restricted maximum likelihood approach (Wood, 2011). This method for fitting the GAM eliminates uninformative predictors automatically - an alternative to traditional model selection techniques like forward or backward selection (Marra and Wood, 2011). This means that if an irrelevant predictor such as DEM-derived slope convexity were included in the predictor set, the resulting GAM would ignore that predictor.

After a GAM was fit to present-day climates, the same statistical model was then used to downscale TraCE-21ka outputs from each decade between 10.5 and 7 ka. The results were then remapped onto a grid to create spatially-explicit winter rainfall estimates for each decade.

\subsection{Neolithic Settlement Data}

Neolithic settlements are not uniformly distributed in space, and settlement patterns can bias the site-level climate change signal in comparison to the regional averages. To address this potential bias, the stack of downscaled winter rainfall estimates was spatially queried at the locations of known Neolithic sites in Anatolia and the Aegean littoral. Rainfall data were extracted for the entire period between 10.5 and $7 \mathrm{ka}$, rather than the spans of the sites' habitations, in order to isolate the climate patterns in the local landscapes colonized, occupied, or abandoned by Neolithic groups. The sample of 59 Neolithic sites from Brami (2014) was used for the spatial queries to facilitate comparison with that study and the chronological patterns discussed therein (Fig. 2). After Brami, the sites were assigned to one of four sub-regions representing both geographic proximity and similarity in material culture: central Anatolia, western Anatolia, Greece, and Thrace. 

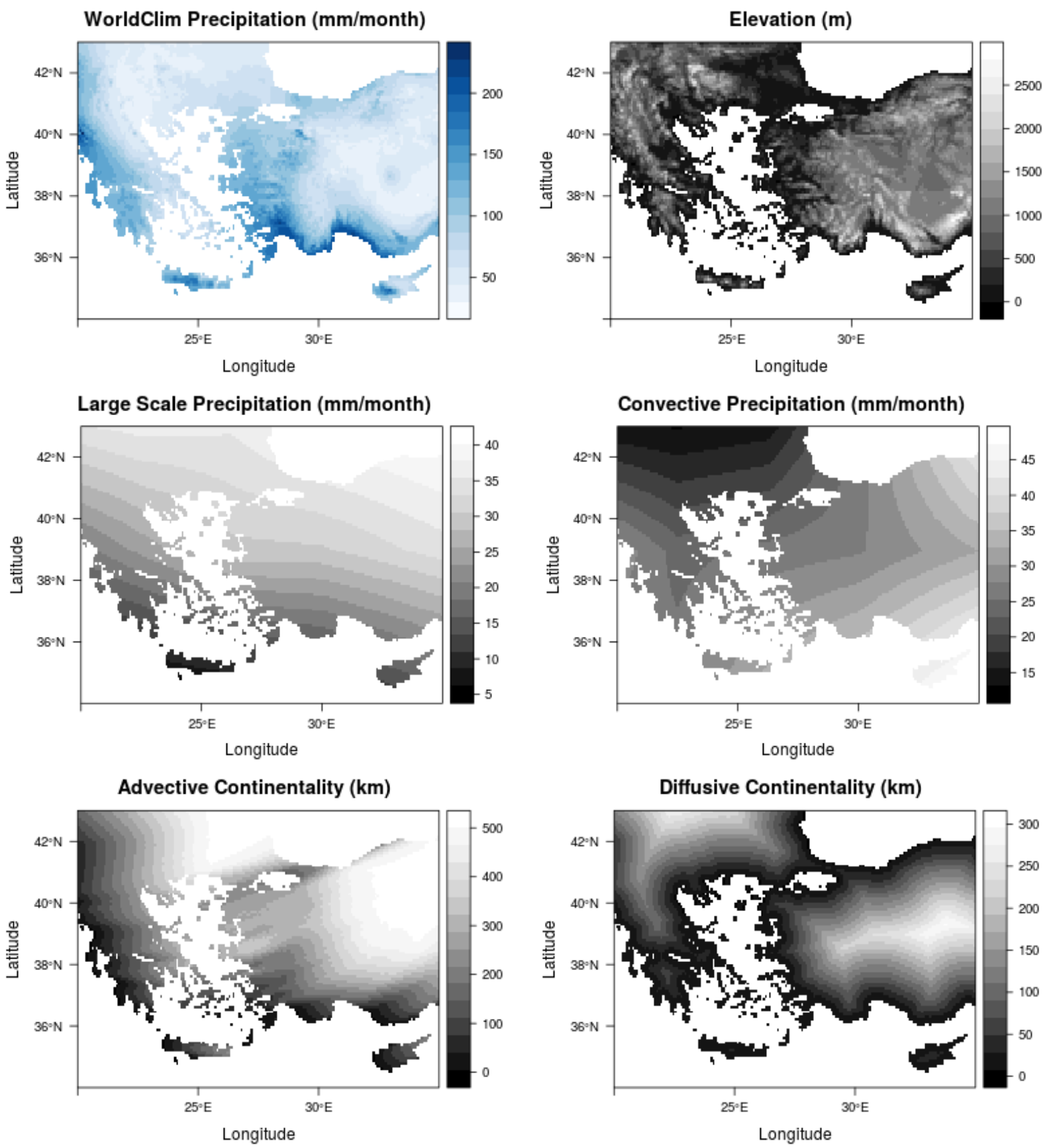

Figure 1: Observed climate data (predictand) and the 5 variables derived from the GCM and/or DEM (predictors). From left to right: observed WorldClim average winter precipitation, SRTM elevation, TraCE-21ka large scale precipitation, TraCE-21ka convective precipitation, diffusive continentality (Euclidean distance to the sea), advective continentality (Euclidean distance to the sea in the direction of the prevailing wind in TraCE-21ka). 


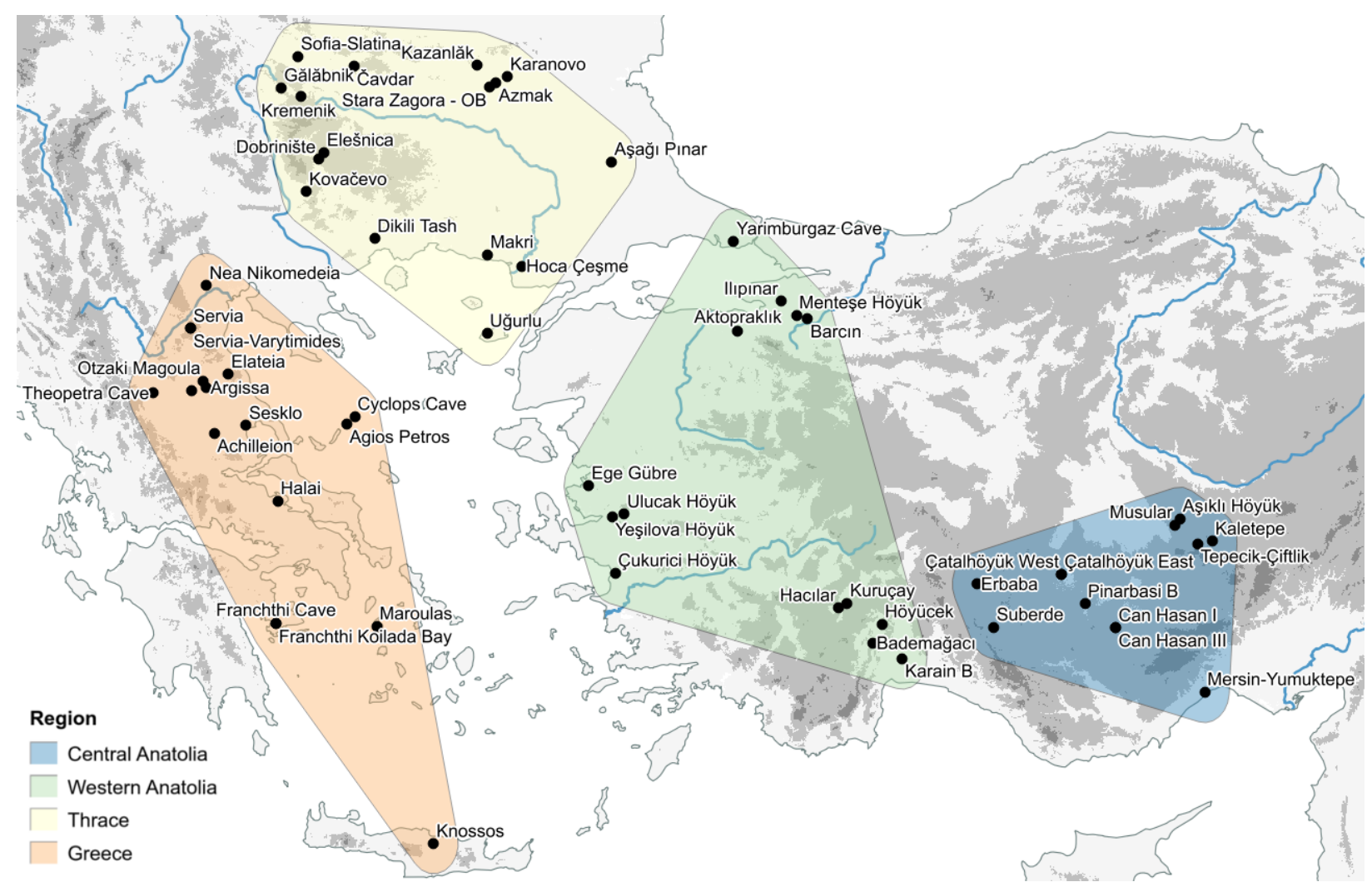

Figure 2: Spatial distribution of the 59 Neolithic sites and regional groupings after Brami (2014). Regional groupings reflect both geographic proximity and similarity in material culture. 


\section{Results}

\subsection{GAM Performance}

The computed nonlinear transfer functions (and confidence bands) that relate each predictor to GAM-estimated winter rainfall are presented in Fig. 3. The plots are scaled and centered to show the relative impact of each predictor on rainfall estimates. For reference, the function for a predictor unrelated to estimated winter rainfall would be approximate a horizontal line. The GAM reduces rainfall estimates when either TraCE-21ka large-scale precipitation or convective precipitation is below $25 \mathrm{~mm}$ or above $35 \mathrm{~mm}$, and increases rainfall estimates when these predictors are between those values. The GAM appears to be correcting biases in the distributions of both raw TraCE-21ka outputs. The GAM captures an inverse relationship between both continentality indices and precipitation. In both cases, increasing continentality leads to a nearly linear decrease in precipitation up to a distance threshold. The effect of diffusive continentality ceases beyond $250 \mathrm{~km}$ from the coast, but the effect of advective continentality continues until $400 \mathrm{~km}$. The transfer function for elevation is more difficult to interpret, but increasing elevation slightly increases precipitation overall. The confidence bands around the elevation transfer function expand at elevations above $2,000 \mathrm{~m}$ due to the low number of data points in that range.

These transfer functions effectively capture the spatial distribution of modern-day winter precipitation. The model explains $74 \%$ of the variance in the WorldClim data, half of the GAM estimates are within $13 \%$ of the observed rainfall total, and the root mean square error of the model is $18.58 \mathrm{~mm}$. The model residuals are normally distributed on the scale of the linear predictor (Fig. 3).

Mapping the residuals back onto the northeastern Mediterranean reveals the model's spatial reconstruction skill (Fig. 4). The model errors are spatially autocorrelated; the model performs poorly in discrete areas like the southern coast of Anatolia and the Troodos Mountains of Cyprus. These errors appear to reflect an orographic effect from coastal mountain ranges that the model cannot capture with the current predictor set. Other, less-pronounced error clusters such as those in the Cyclades may reflect regions where the WorldClim data were calculated from few or no weather stations. Regardless of these discrete clusters, model error is small overall and a minor percentage of total observed precipitation.

\subsection{Early Holocene Winter Rainfall Estimates}

The estimate of mean winter rainfall across the entire northeastern Mediterranean for each decade from 10.5 to $7 \mathrm{ka}$ is shown in Fig. 5. The decadal data are further smoothed to highlight long-term precipitation trends. There is a gradual drying trend during the initial 700 years of the simulation, followed by 1,000 years of more stable rainfall. An arid period extends from 8.7 to $8.1 \mathrm{ka}$, with a peak at $8.6 \mathrm{ka}$, followed by a return to stable conditions. The standard deviation of precipitation over space follows a similar pattern, although the reduction in rainfall variability after $8.7 \mathrm{ka}$ appears to be less abrupt than the reduction in rainfall averages and more part of a longer-term trend.

The spatial structure of this dry period was determined by subtracting a map of rainfall before the drought from one during the drought (Fig. 6). The change in rainfall is not 


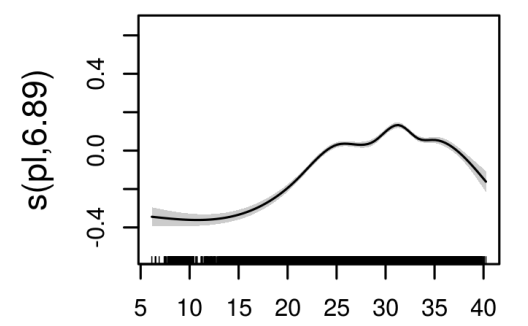

Large Scale Precipitation $(\mathrm{mm})$

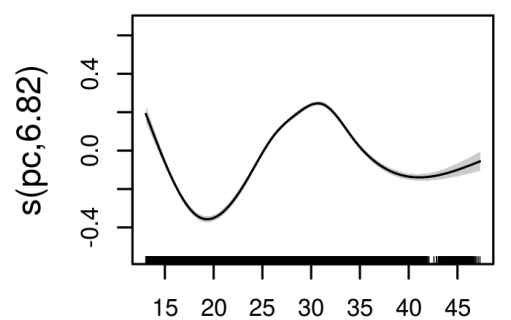

Convective Precipitation ( $\mathrm{mm})$
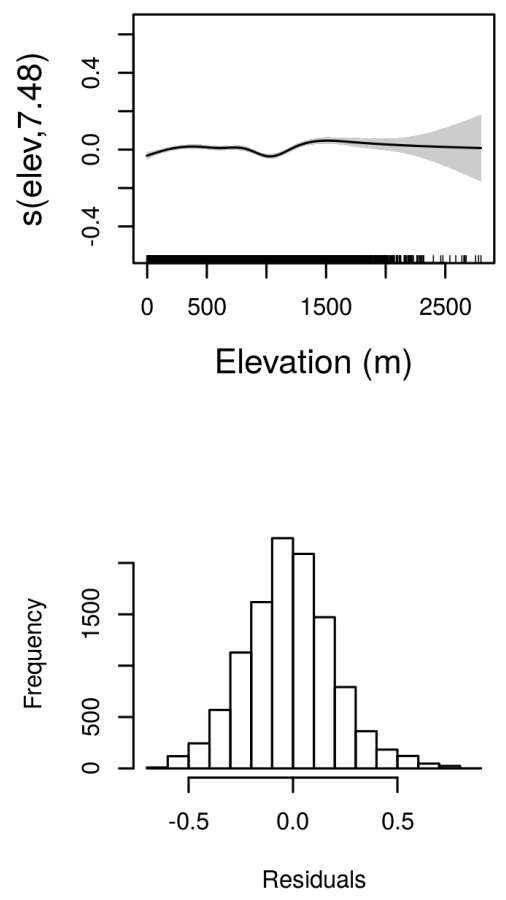

Figure 3: The nonlinear transfer functions (cubic regression splines), calculated by mgcv, showing the relative influence of the five predictor variables on estimated winter rainfall, and a histogram of the model residuals. The shaded areas represent 95\% confidence intervals around each smooth function. The y-axis labels are of the form $s(c o v$, edf) where $s$ denotes a spline function of the covariate cov with estimated degrees of freedom edf. The y-axes are centered and scaled to the linear predictor, but the x-axes remain in the original scale of each predictor variable. The rug plots along the x-axis of each plot correspond to the distribution of that covariate. 

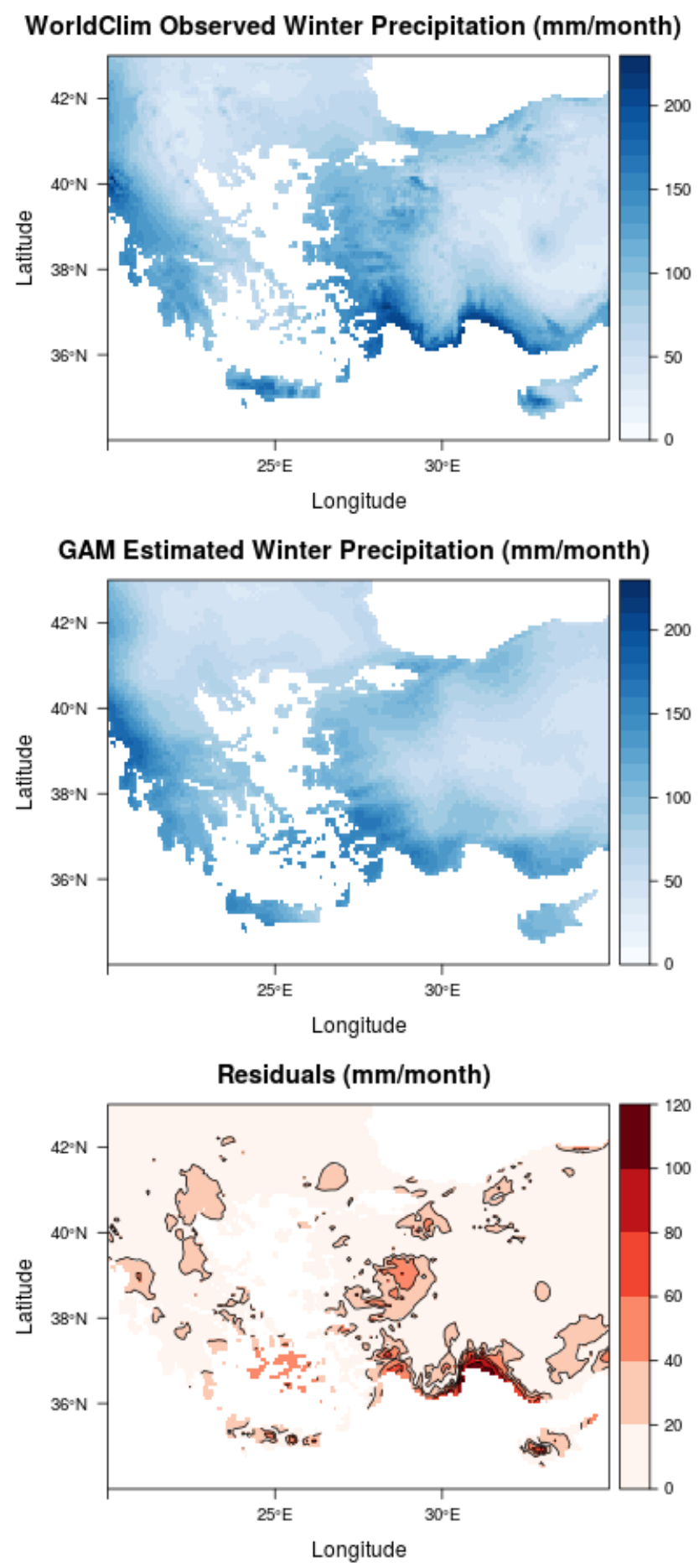

Figure 4: Maps of WorldClim observed precipitation from the modern period (AD 1940 - 2000), GAM estimates of winter precipitation during the modern period, and the absolute deviance (residuals) between the two. The residual map is grouped into discrete color classes to emphasize zones of similar model error. 

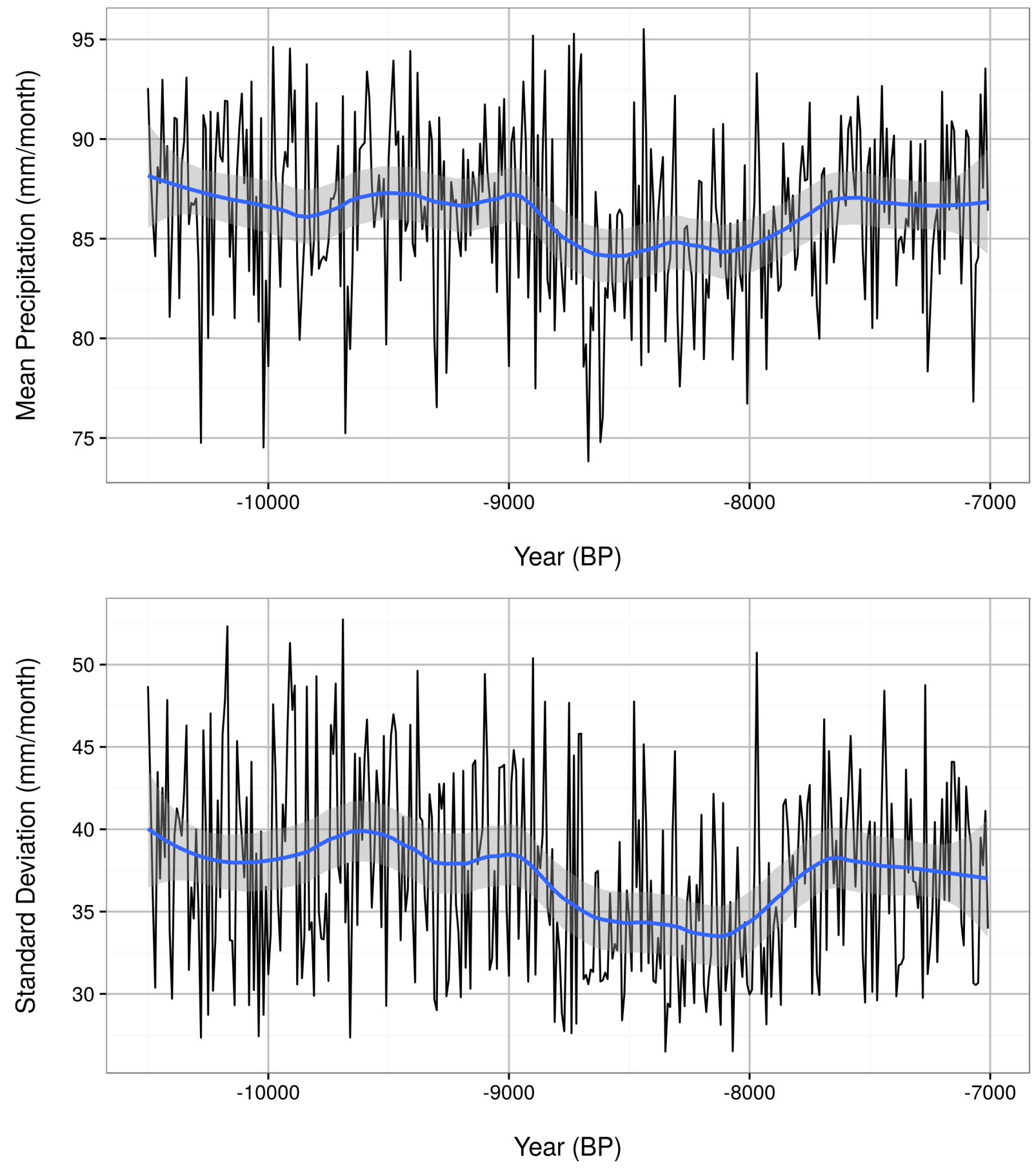

Figure 5: Areal average (top) and standard deviation (bottom) of GAM-downscaled winter rainfall over the entire study area. The black lines represent the raw decadal data. The blue lines and shaded confidence bands are LOESS smooths of the decadal data. 
homogeneous across space, with an increase in aridity focused on a broad belt of land between roughly $\mathrm{N} 36^{\circ}$ and $\mathrm{N} 40^{\circ}$. Western Greece, in particular the northern half of the Peloponnese, and the southern Aegean region in Anatolia are most impacted by the drought, receiving an average of 20 to $40 \mathrm{~mm}$ less precipitation during each winter month. Notably, Thrace and parts of the Black Sea and Mediterranean coasts of Anatolia show a mild increase in precipitation in opposition to the overall drying trend.

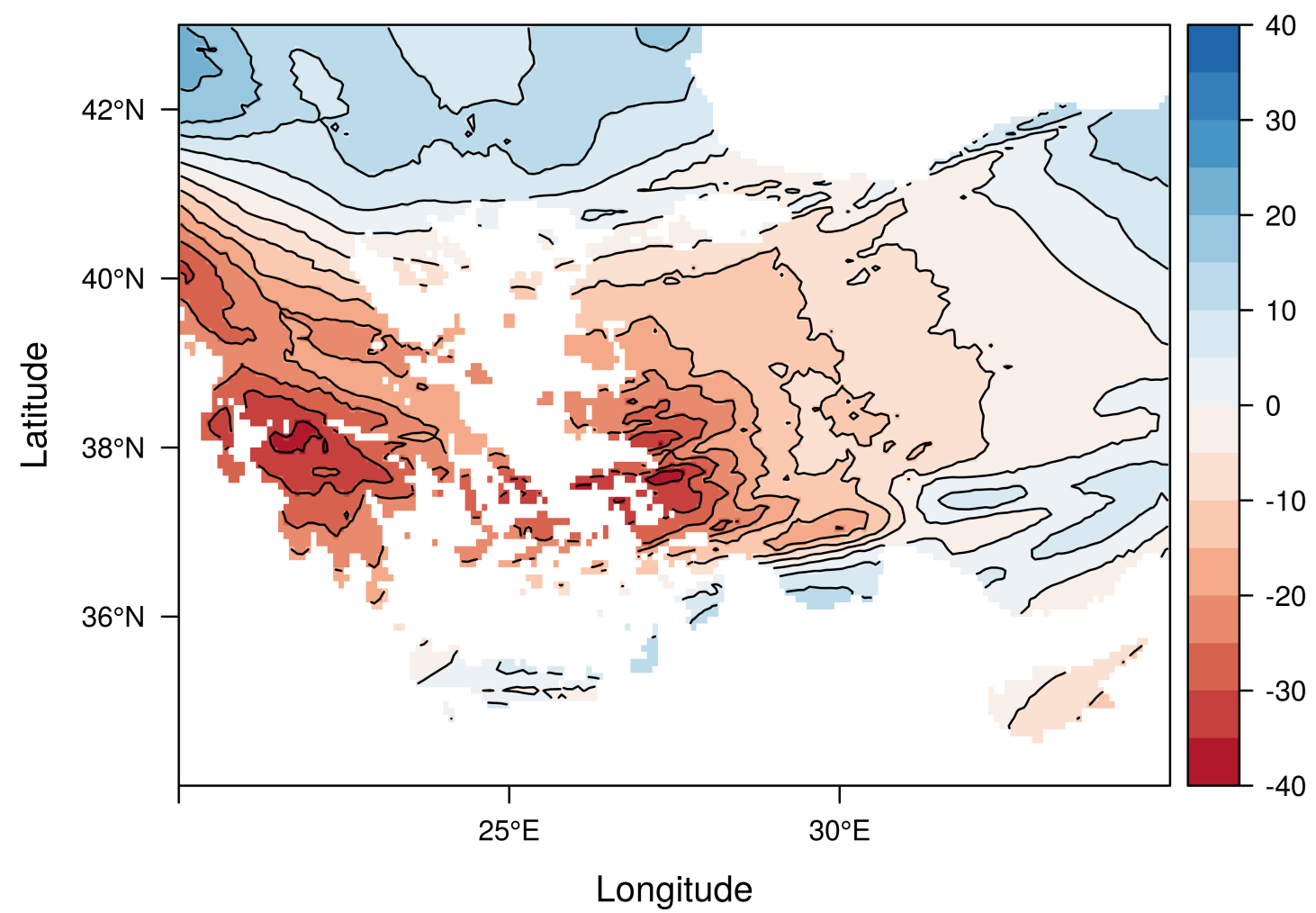

Figure 6: The spatial structure of climate change in the early ninth millennium BP, represented as the difference between winter rainfall averages in the century after 9.6 ka and and the century after 8.6 ka. Negative values correspond to decreasing rainfall over this period.

\subsection{Winter Rainfall in Neolithic Landscapes}

The distributions of winter rainfall sampled at the 59 Neolithic site locations display the same patterning as the area-averaged and fully-gridded datasets (Fig. 7). Landscapes in Greece and western Anatolia experienced drought conditions in line with the region-wide averages, while those in central Anatolia experienced no change in rainfall and those in Thrace experienced wetter winters. The standard deviation in rainfall decreases in western Anatolia, Thrace, and Greece, but not in central Anatolia. Whether a region received more or less winter rainfall during the regional drought reflects its absolute rainfall totals, with decreasing rainfall in wetter regions and increasing rainfall in drier regions. As a result, the overlap between the regional precipitation distributions also increases after 8.6 ka. 


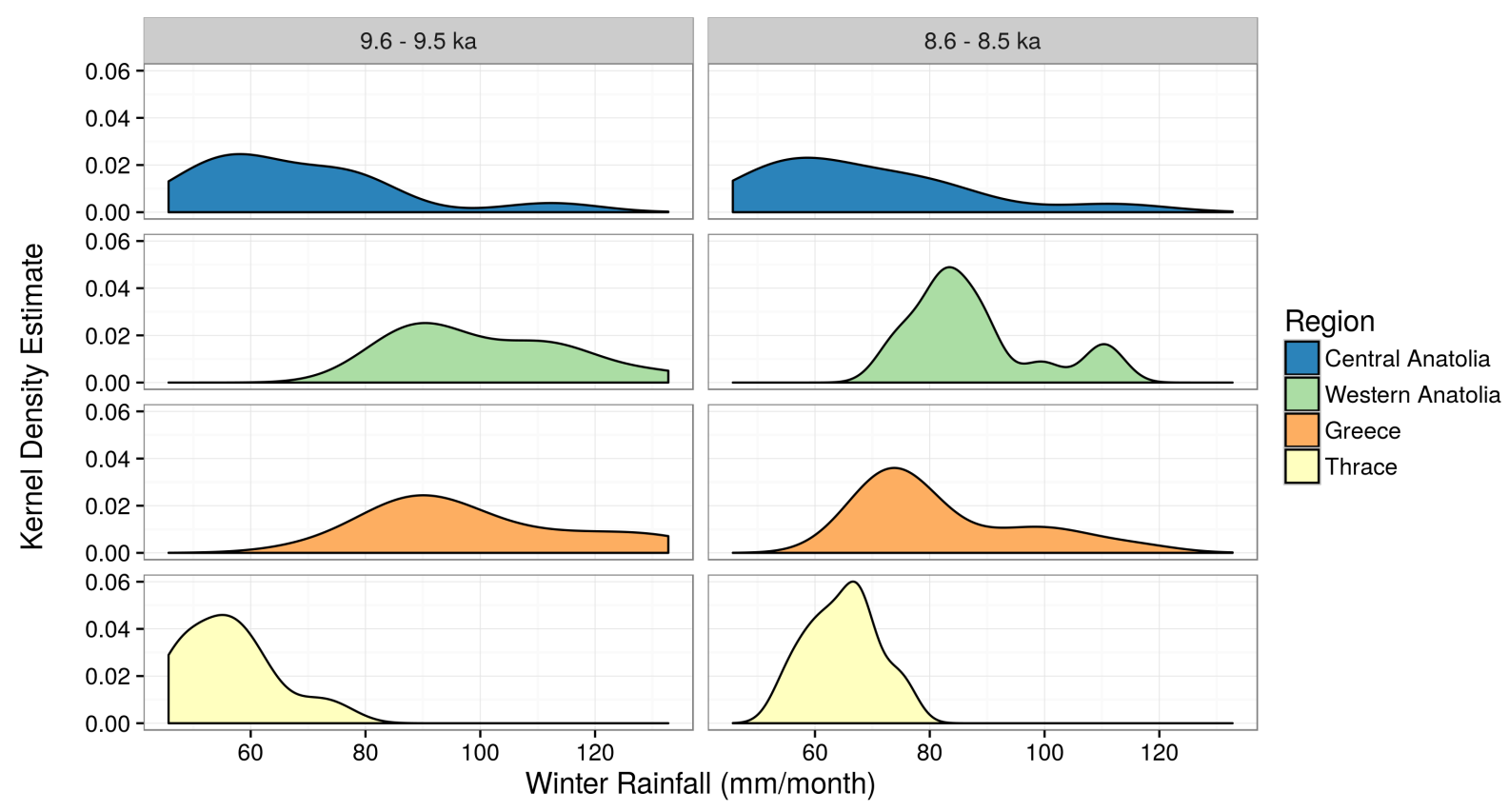

Figure 7: Kernel density estimates of the distribution of winter rainfall at 59 Neolithic landscapes in four archaeological regions for the same time steps as Fig. 6 (9.6 to 9.5 ka and 8.6 to $8.5 \mathrm{ka}$ ). Median rainfall in western Anatolia and Greece decreases over time; the median rainfall in Thrace increases. The increasing overlap between the distributions in the second time step indicates a decrease in inter-regional variability, and the reduction in the spreads of each distribution indicates a decrease in intra-regional variability. Central Anatolian sites experience very little change in the distribution of rainfall. 


\section{Discussion}

The timing and duration of the drying event as reconstructed from the downscaled GCM simulation is consistent with global proxy records that show widespread climatic deterioration from around 8.6 to $8 \mathrm{ka}$, driven by some combination of solar variability, freshwater inputs to the Atlantic ocean from the collapsing Laurentide Ice Sheet, and atmosphere-ocean feedbacks internal to the climate system (Rohling and Pälike, 2005; Wanner et al., 2011). The latter two processes appear to dominate in the TraCE-21ka simulation, as it reproduces the temporal behavior of climatic deterioration without explicit changes to solar forcing beyond those induced by the orbital parameters. Previous analyses of TraCE-21ka and related paleoclimate simulations using CCSM3 have shown that this GCM is able to capture the cascading atmosphere-ocean feedbacks initiated by glacial meltwater discharge (He, 2011; Wagner et al., 2013; Cheng et al., 2014), lending support to the simulation's ability to capture centennial-scale climate evolution during the ninth millennium BP accurately.

Because the predictor and predictand data used to develop the GAM are only approximations, the downscaled rainfall data are more safely interpreted as estimates of past climates than as exact reconstructions. Errors in the WorldClim data used to calibrate the GAM may bias resulting paleoclimate estimates. So too will biases in the GCM-derived predictors. Although TraCE-21ka reproduces the centennial scale climate evolution of the early Holocene, the simulation's behavior on sub-centennial time scales is more probabilistic. Rainfall patterns in any particular year of the simulation will not be the same as real-world patterns in that year, even though the distribution of rainfall in any particular century might be statistically indistinguishable from what did occur.

Future downscaling efforts should embrace these uncertainties and the inherently probabilistic nature of GCMs. The method of Steiger et al. (2012) uses GCM data to generate statistical ensembles of possible climate states, and integrates climate signals from paleoclimate proxies to update the ensemble prediction. Meteorologists use a similar statistical framework to generate five-day leading forecasts by integrating an ensemble of weather prediction models with each successive day's observed weather. After determining the time scale at which the TraCE-21ka simulation becomes purely probabilistic, it will be possible to use the GAM-downscaled data as ensemble members in this data assimilation approach. Combining the complementary lines of evidence from climate models and proxy records will lead to more robust and flexible reconstructions overall.

The spatial pattern of climate change in the current simulation-only estimates are consistent with regional proxy records, however. The simulated drying event starting at 8.7 ka manifests differently around the Aegean Sea (Fig. 6 -7). Greece and western Anatolia, coastal regions watered by storms driven off the Mediterranean by westerly winds, receive less precipitation after $8.7 \mathrm{ka}$. More continental areas - Thrace and central Anatolia — are either less impacted by drought or experience increases in winter precipitation. Pollen assemblages from Aegean Sea cores are consistent with more arid winters in Greece after 8.4 ka BP (Kotthoff et al., 2008); diatom assemblages from the Ioannina basin in western Greece suggest a similar trend on a more local scale (Wilson et al., 2008). Consistent with the simulation results, there is comparatively little evidence for pronounced climate change 
in central Anatolia during the period (Düring, 2013, and references therein); the landscape around Çatalhöyük itself experienced stable to slightly drier winters at around 8.6 ka BP (Lewis et al., 2016). In Thrace, however, pollen-based vegetation reconstructions (Connor et al., 2013) and diatom-based lake-level estimates (Zhang et al., 2014) both show moister conditions after about $8.5 \mathrm{ka} \mathrm{BP}$, and cocolithophore assemblages from the North Aegean attest to high freshwater inputs from between 8.8 and 7.9 ka BP (Triantaphyllou, 2014). As discussed in Section 1, the use of such proxy records in isolation introduces issues of chronology, bias, and spatial representativeness, but the overall congruence with physicallyconsistent and continuous climate model outputs lends support to the overall picture of a change in the spatial structure of rainfall around 8.6 ka.

The drought in the Aegean littoral, as represented in the downscaled GCM simulation, appears to result from a weakening of the winter storm tracks delivering rain to Greece and western Anatolia. The simultaneous increase of rainfall over Thrace also suggests a northward deflection of these storm tracks. The existence of a climate-response boundary at roughly $\mathrm{N} 40^{\circ}$, structured by westerly circulation, has been proposed previously on the basis proxies primarily in Europe and the western Mediterranean (Magny et al., 2003; Berger and Guilaine, 2009; Magny et al., 2013); until now the structure of this boundary in the eastern Mediterranean has been underdetermined.

The change in rainfall at 8.6 ka is spatially heterogeneous, but this heterogeneity serves to blur the boundaries between previously distinct climate zones, just as a uniform decrease in rainfall would have preserved regional contrasts. Thus a more homogeneous climate landscape emerges as wetter regions receive less rain and drier regions more rain. The standard deviation of rainfall accumulations across space decreases between 8.7 ka and 8.1 ka (Fig. 5), and any two locations in the northeastern Mediterranean are more likely to experience similar winter rainfall accumulations during this period than at any time before or after. Rainfall in the landscapes occupied by Neolithic settlements follows a similar pattern; inter-regional variability decreases and the range of rainfall totals in all regions is reduced (Fig. 7).

The emergence of a more homogeneous winter rainfall regime across the Aegean littoral would have reduced barriers to farmers by dampening the regional climate contrasts posing challenges to innovation. Present-day Mediterranean farmers draw on extensive knowledge of local rainfall patterns to decide when to plant and harvest their crops, or how to tune their land-use and herd-management strategies (Halstead, 2014). Assuming early farming traditions were likewise sensitive to variability in local rainfall in space and time, reduced variability would have allowed Neolithic groups to better anticipate climate conditions in a newly-occupied landscape and to adapt their food production accordingly. The similarity between the local landscapes of the earliest western Anatolian Neolithic sites and those of earlier Neolithic sites in southwest Asia (Van Andel and Runnels, 1995; Groenhuijzen et al., 2015; Horejs et al., 2015) does suggest a degree of local adaptation and habitat tracking involved in early forays into the Aegean. Changing rainfall could also dampen regional contrasts via second-order environmental effects such as a reduction of forest cover and soil stability or a disruption of game animal mobility patterns (Schoop, 2005; Berger and Guilaine, 2009). Aridity along the Aegean littoral would have also eliminated social barriers 
to Neolithic expansion by disrupting food production in previously established populations of Mesolithic hunter-gatherers (Düring, 2013).

None of these explanations are mutually exclusive, and regardless of the particular proximate mechanisms through which climate impacted Neolithic dispersal, the broader correlation between rainfall patterns and Neolithic settlement patterns highlights the importance of climate variability and predictability, rather than space and time averages, in social processes such as colonization and migration. This interpretation is consistent with recent work on the role of spatial heterogeneity in the dispersal of early modern humans (Wren et al., 2014), and may reflect deeper interactions between environmental variability and dispersal in adaptive systems (Grove, 2014). Downscaled paleoclimate simulations are an essential tool for understanding these interactions, as climate models can help to bridge the gap between the static archaeological record and the dynamic social-ecological processes that generated it.

\section{Conclusion}

In this study I used a climate model to map the spatial structure underlying changes in regional mean winter rainfall during the period of Neolithic dispersal into the Aegean littoral. I used a generalized additive model to downscale winter rainfall from a GCM paleoclimate simulation. The model performed well at reproducing the present-day pattern of rainfall, and it produced physically-interpretable estimates of past rainfall consistent with regional and global paleoclimate proxy records. The model also revealed spatially-heterogeneous regional impacts of this global climate event; only the humid coastal regions of the Aegean littoral experienced a major drought. The result of this spatially heterogeneous climate event was, conversely, more homogeneous regional rainfall. Neolithic groups moving out from southwest Asia during the ninth millennium BP would have encountered new landscapes with a more familiar, and predictable, rainfall regime. These findings emphasize the importance of estimating changes in spatial variability patterns when assessing the impact of climate change on social change in the past.

\section{Acknowledgements}

I would like to thank C.M. Barton, K. Michelaki, and M.A. Janssen, as well as two anonymous reviewers, for their helpful comments on previous versions of this manuscript. TraCE-21ka was made possible by the DOE INCITE computing program, and supported by NCAR, the NSF P2C2 program, and the DOE Abrupt Change and EaSM programs.

\section{References}

Alemán, P.A.M., García, E., Aleman, P.A.M., Garcia, E., 1981. The Variability of Rainfall in Mexico and Its Determination by Means of the Gamma Distribution. Geografiska Annaler. Series A, Physical Geography $63,1$.

Berger, J.F., Guilaine, J., 2009. The 8200 cal BP abrupt environmental change and the Neolithic transition: A Mediterranean perspective. Quaternary International 200, 31-49. 
Brami, M.N., 2014. A graphical simulation of the 2,000-year lag in Neolithic occupation between Central Anatolia and the Aegean basin. Archaeological and Anthropological Sciences , 1-9.

Brayshaw, D.J., Rambeau, C.M.C., Smith, S.J., 2011. Changes in the Mediterranean climate during the Holocene: insights from global and regional climate modelling. The Holocene 21, 15-31.

Brulhet, J., Texier, D., Noblet, N., Paillard, D., Degnan, P., Becker, A., Cortes, A., Pinedo, P., Recreo Jiménez, F., Agüero Prieto, A., Others, Ruiz García, C., Lomba Falcón, L., Torres Pérez-Hidalgo, T.J., Lucini, M., Ortiz Menéndez, J.E., Marbaix, P., Kageyama, M., Lunt, D., 2003. Deliverable D8b: Development of the physical/statistical downscaling methodology and application to climate model CLIMBER for BIOCLIM Workpackage 3. Work Package 3, Simulation of the future evolution of the biosphere system using the hierarchical strategy.

Burke, A., Levavasseur, G., James, P.M.A., Guiducci, D., Izquierdo, M.A., Bourgeon, L., Kageyama, M., Ramstein, G., Vrac, M., 2014. Exploring the impact of climate variability during the Last Glacial Maximum on the pattern of human occupation of Iberia. Journal of Human Evolution 73, 35-46.

Cheng, J., Liu, Z., He, F., Otto-Bliesner, B., Brady, E., Lynch-Stieglitz, J., 2014. Model-proxy comparison for overshoot phenomenon of atlantic thermohaline circulation at bølling-allerød. Chinese Science Bulletin $59,4510-4515$.

Clare, L., Weninger, B., 2010. Social and biophysical vulnerability of prehistoric societies to Rapid Climate Change. Documanta Praehistorica 37, 269-284.

Collins, W.D., Bitz, C.M., Blackmon, M.L., Bonan, G.B., Bretherton, C.S., Carton, J.a., Chang, P., Doney, S.C., Hack, J.J., Henderson, T.B., Kiehl, J.T., Large, W.G., McKenna, D.S., Santer, B.D., Smith, R.D., 2006. The Community Climate System Model Version 3 (CCSM3). J. Clim. 19, 2122-2143.

Connor, S.E., Ross, S.A., Sobotkova, A., Herries, A.I.R., Mooney, S.D., Longford, C., Iliev, I., 2013. Environmental conditions in the SE Balkans since the Last Glacial Maximum and their influence on the spread of agriculture into Europe. Quaternary Science Reviews 68, 200-215.

Düring, B.S., 2013. Breaking the Bond: Investigating The Neolithic Expansion in Asia Minor in the Seventh Millennium BC. Journal of World Prehistory 26, 75-100.

Flohr, P., Fleitmann, D., Matthews, R., Matthews, W., Black, S., 2016. Evidence of resilience to past climate change in southwest asia: Early farming communities and the 9.2 and 8.2 ka events. Quaternary Science Reviews 136, 23-39.

Gettelman, A., Rood, R.B., 2016. Demystifying Climate Models. Springer.

Groenhuijzen, M.R., Kluiving, S.J., Gerritsen, F.A., Künzel, M., 2015. Geoarchaeological research at barcin höyük: Implications for the initial neolithic occupation of northwest anatolia. Quaternary International $359,452-461$.

Grove, M., 2014. Evolution and dispersal under climatic instability: a simple evolutionary algorithm. Adaptive Behavior 22, 235-254.

Halstead, P., 2014. Two oxen ahead: pre-mechanized farming in the Mediterranean. John Wiley \& Sons.

He, F., 2011. Simulating Transient Climate Evolution of the Last Deglatiation with CCSM3. Ph.D. thesis. University of Wisconsin-Madison. Madison.

Hijmans, R.J., 2016. raster: Geographic Data Analysis and Modeling. R package version 2.5-8.

Hijmans, R.J., Cameron, S.E., Parra, J.L., Jones, P.G., Jarvis, A., 2005. Very high resolution interpolated climate surfaces for global land areas. International Journal of Climatology 25, 1965-1978.

Hofmanová, Z., Kreutzer, S., Hellenthal, G., Sell, C., Diekmann, Y., Díez-del Molino, D., van Dorp, L., López, S., Kousathanas, A., Link, V., et al., 2016. Early farmers from across europe directly descended from neolithic aegeans. Proceedings of the National Academy of Sciences, 201523951.

Horejs, B., Milić, B., Ostmann, F., Thanheiser, U., Weninger, B., Galik, A., 2015. The aegean in the early 7th millennium bc: Maritime networks and colonization. Journal of World Prehistory 28, 289-330.

Korhonen, N., Venäläinen, a., Seppä, H., Järvinen, H., 2013. Statistical downscaling of a climate simulation of the last glacial cycle: temperature and precipitation over Northern Europe. Climate of the Past Discussions 9, 3371-3398.

Kotthoff, U., Pross, J., Mller, U.C., Peyron, O., Schmiedl, G., Schulz, H., Bordon, A., 2008. Climate dynamics in the borderlands of the aegean sea during formation of sapropel $\{\mathrm{S} 1\}$ deduced from a marine 
pollen record. Quaternary Science Reviews 27, 832 - 845 .

Lemmen, C., Wirtz, K.W., 2014. On the sensitivity of the simulated European Neolithic transition to climate extremes. Journal of Archaeological Science 51, 65-72. 1203.0222.

Levavasseur, G., Vrac, M., Roche, D.M., Paillard, D., Martin, A., Vandenberghe, J., 2011. Present and LGM permafrost from climate simulations: Contribution of statistical downscaling. Climate of the Past 7, $1225-1246$.

Lewis, J.P., Leng, M.J., Dean, J.R., Marciniak, A., Bar-Yosef Mayer, D.E., Wu, X., 2016. Early holocene palaeoseasonality inferred from the stable isotope composition of unio shells from çatalhöyük, turkey. Environmental Archaeology, 1-17.

Magny, M., Bgeot, C., Guiot, J., Peyron, O., 2003. Contrasting patterns of hydrological changes in europe in response to holocene climate cooling phases. Quaternary Science Reviews 22, $1589-1596$.

Magny, M., Combourieu-Nebout, N., de Beaulieu, J.L., Bout-Roumazeilles, V., Colombaroli, D., Desprat, S., Francke, A., Joannin, S., Ortu, E., Peyron, O., Revel, M., Sadori, L., Siani, G., Sicre, M.A., Samartin, S., Simonneau, A., Tinner, W., Vannière, B., Wagner, B., Zanchetta, G., Anselmetti, F., Brugiapaglia, E., Chapron, E., Debret, M., Desmet, M., Didier, J., Essallami, L., Galop, D., Gilli, A., Haas, J.N., Kallel, N., Millet, L., Stock, A., Turon, J.L., Wirth, S., 2013. North-south palaeohydrological contrasts in the central mediterranean during the holocene: tentative synthesis and working hypotheses. Climate of the Past 9, 2043-2071.

Maraun, D., Wetterhall, F., Ireson, A., Chandler, R., Kendon, E., Widmann, M., Brienen, S., Rust, H., Sauter, T., Themeßl, M., et al., 2010. Precipitation downscaling under climate change: Recent developments to bridge the gap between dynamical models and the end user. Reviews of Geophysics 48.

Marra, G., Wood, S.N., 2011. Practical variable selection for generalized additive models. Computational Statistics and Data Analysis 55, 2372-2387.

Pickett, S.T.A., Cadenasso, M.L., 1995. Landscape Ecology: Spatial Heterogeneity in Ecolocial Systems. Science 269, 331-334.

R Core Team, 2015. R: A Language and Environment for Statistical Computing. R Foundation for Statistical Computing. Vienna, Austria.

Rohling, E.J., Pälike, H., 2005. Centennial-scale climate cooling with a sudden cold event around 8,200 years ago. Nature 434, 975-979.

Schoop, U.D., 2005. The Late Escape of the Neolithic from the Central Anatolian Plain. Byzas 2, 41-58.

Shennan, S., Downey, S.S., Timpson, A., Edinborough, K., Colledge, S., Kerig, T., Manning, K., Thomas, M.G., 2013. Regional population collapse followed initial agriculture booms in mid-Holocene Europe. Nature Communications 4, 2486.

Steiger, N.J., Hakim, G.J., Steig, E.J., Battisti, D.S., Roe, G.H., 2012. Climate Field Reconstruction via Data Assimilation. J. Climate 26.

Tingley, M.P., Craigmile, P.F., Haran, M., Li, B., Mannshardt, E., Rajaratnam, B., 2012. Piecing together the past: Statistical insights into paleoclimatic reconstructions. Quaternary Science Reviews 35, 1-22.

Triantaphyllou, M.V., 2014. Coccolithophore assemblages during the holocene climatic optimum in the ne mediterranean (aegean and northern levantine seas, greece): paleoceanographic and paleoclimatic implications. Quaternary International 345, 56-67.

Van Andel, T.H., Runnels, C.N., 1995. The earliest farmers in europe. Antiquity 69, 481-500.

Vrac, M., Marbaix, P., Paillard, D., Naveau, P., 2007. Non-linear statistical downscaling of present and LGM precipitation and temperatures over Europe. Climate of the Past 3, 669-682.

Wagner, A.J., Morrill, C., Otto-Bliesner, B.L., Rosenbloom, N., Watkins, K.R., 2013. Model support for forcing of the 8.2 ka event by meltwater from the hudson bay ice dome. Climate Dynamics 41, 2855-2873.

Wanner, H., Solomina, O., Grosjean, M., Ritz, S.P., Jetel, M., 2011. Structure and origin of holocene cold events. Quaternary Science Reviews 30, 3109-3123.

Weninger, B., Clare, L., Gerritsen, F., Horejs, B., Krau \s s, R., Linstädter, J., Özbal, R., Rohling, E.J., 2014. Neolithisation of the Aegean and Southeast Europe during the 66006000 calBC period of Rapid Climate Change. Documenta Praehistorica 41.

Wilby, R., Charles, S., Zorita, E., Timbal, B., Whetton, P., Mearns, L., 2004. Guidelines for use of climate 
scenarios developed from statistical downscaling methods. supporting material of the intergovernmental panel on climate change (ipcc), prepared on behalf of task group on data and scenario support for impacts and climate analysis (tgica). .

Wilby, R.L., Wigley, T.M.L., Conway, D., Jones, P.D., Hewitson, B.C., Main, J., Wilks, D.S., 1998. Statistical downscaling of general circulation model output: A comparison of methods. Water Resources Research 34, 2995.

Wilson, G.P., Reed, J.M., Lawson, I.T., Frogley, M.R., Preece, R.C., Tzedakis, P.C., 2008. Diatom response to the last glacial-interglacial transition in the ioannina basin, northwest greece: implications for mediterranean palaeoclimate reconstruction. Quaternary Science Reviews 27, 428-440.

Wood, S.N., 2006. Generalized Additive Models: An Introduction with R. CRC press.

Wood, S.N., 2011. Fast stable restricted maximum likelihood and marginal likelihood estimation of semiparametric generalized linear models. Journal of the Royal Statistical Society: Series B (Statistical Methodology) 73, 3-36.

Wren, C.D., Xue, J.Z., Costopoulos, A., Burke, A., 2014. The role of spatial foresight in models of hominin dispersal. Journal of human evolution 69, 70-8.

Zhang, X., Reed, J., Wagner, B., Francke, A., Levkov, Z., 2014. Lateglacial and holocene climate and environmental change in the northeastern mediterranean region: diatom evidence from lake dojran (republic of macedonia/greece). Quaternary Science Reviews 103, 51 - 66 . 


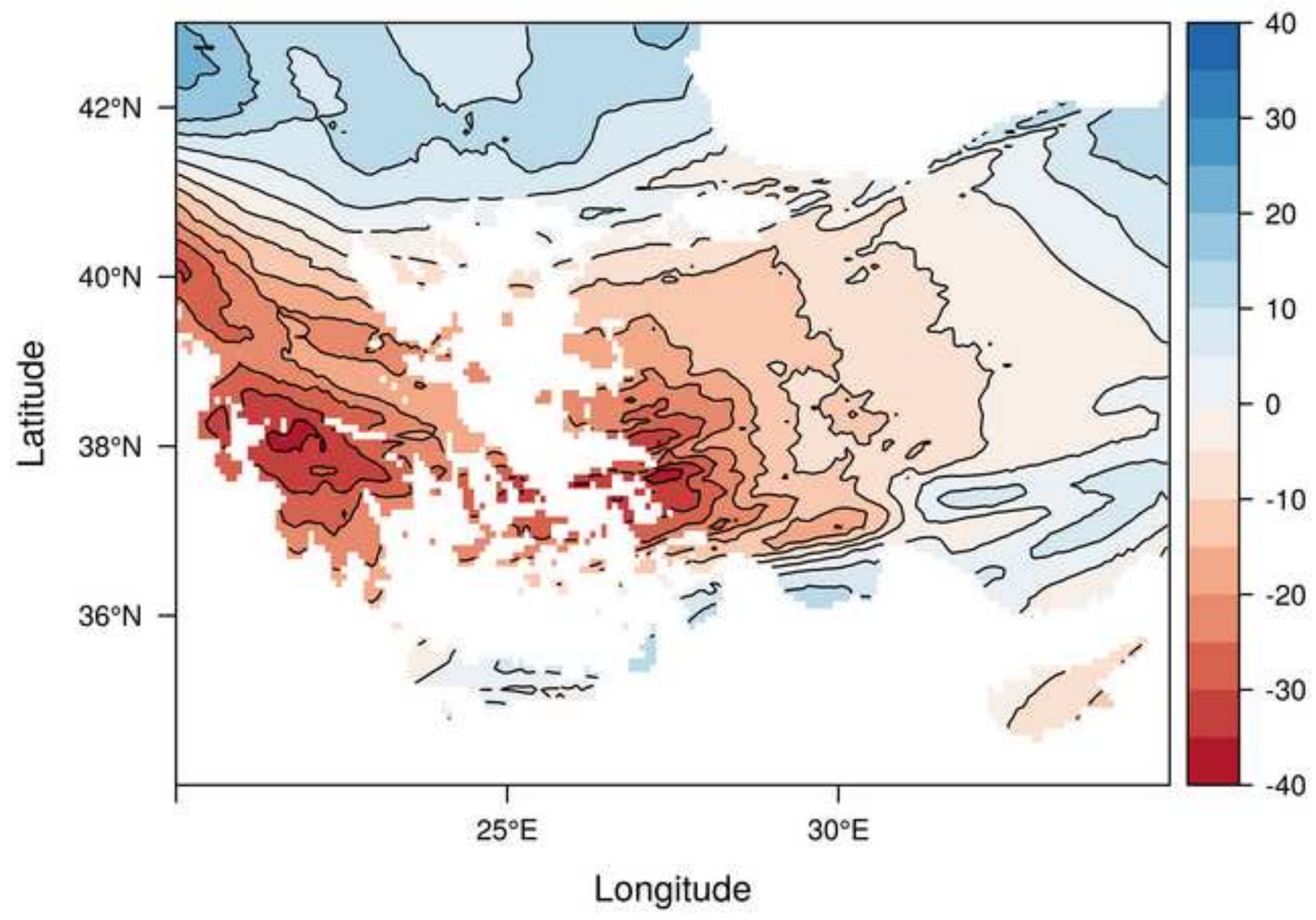

